\title{
LA VIALIDAD INCAICA EN LA PROVINCIA DE SAN JUAN (ARGENTINA)
}

\section{THE INCA ROAD SYSTEM IN SAN JUAN PROVINCE (ARGENTINA)}

\author{
AlejandRo GarcíaA
}

En el último siglo diversos autores han brindado información sobre el recorrido de la vialidad incaica en San Juan y han propuesto distintas alternativas para su trazado (Debenedetti 1917; Rusconi 1962; Raffino 1981; Stehberg 1995; etc.), si bien recién en los últimos años se ha puesto mayor atención a la contrastación empírica de tales formulaciones (García 2011a). Continuando esa senda, en este artículo se brinda un panorama actualizado del avance del conocimiento sobre el tema y una reconstrucción de la vialidad incaica en la provincia.

Palabras clave: Qhapaq Nan, vialidad incaica, San Juan, Argentina.

In the last century several authors provided information on the Inca road system in San Juan and proposed different alternatives about its location (Debenedetti 1917; Rusconi 1962; Raffino 1981; Stehberg 1984; etc.), but only in recent years such formulations began to be empirically tested (Garcia 2011). Continuing on this path, this article gives an update about further knowledge on the subject, as well as a reconstruction of the Inca roads found in the province.

Keywords: Qhapaq Nan, Inca Road System, San Juan, Argentina.

\section{INTRODUCCIÓN}

Como se desprende del clásico trabajo de Debenedetti (1917), la traza de la vialidad incaica en la provincia de San Juan era conocida hace un siglo atrás por los puesteros locales. Desde entonces, los efectos de diversos agentes naturales y de algunas actividades humanas han contribuido a borrar algunos tramos, mientras que la ausencia de un trabajo de síntesis que recogiera la información disponible sobre su trazado ha llevado incluso al surgimiento de algunas dudas sobre su localización.

Las menciones más antiguas registradas en el siglo xx dan cuenta del paso de un tramo del Qhapaq Nan por los valles preandinos de Calingasta e Iglesia (Aparicio 1940; Rusconi 1962; Strube Erdmann 1963), posición curiosamente no compartida por Debenedetti (1917) a pesar de haberlo recorrido y de haber pasado por el Tambo de Tocota (sur del valle de Iglesia), sitio excavado varias décadas después (Berberián et al. 1978). Bárcena (1979) constató la presencia del Qhapaq Ñan en el extremo sur sanjuanino y registró un llamativo sitio que denominó Tambería del Leoncito. Más recientemente (Bárcena 2010), halló los restos de un asentamiento incaico mencionado por Debenedetti como Tamberías y lo denominó Río Seco de los Tambillos I, y observó la senda del camino incaico cerca de la Ruta Provincial

\footnotetext{
A Alejandro García, CONICET (CIgeobio), Facultad de Filosofía y Letras UNCuyo - Facultad de Filosofía, Humanidades y Artes unsJ, e-mail: alegarcia@unsj.edu.ar
} 
412. Aunque no realizó un relevamiento directo, Hyslop (1984) coincidió en señalar el paso del Qhapaq Ñan por los valles preandinos. Por el contrario, Michieli (2001) afirmó su inexistencia en dichos valles, y propuso como alternativa que el Qhapaq Ñan atravesaba longitudinalmente la región precordillerana. Finalmente, García (2011a) registró los sectores actualmente visibles del trazado del Qhapaq Nan entre los sitios de Tocota y Tambería del Leoncito y estableció su localización precisa a través de los valles de Calingasta e Iglesia.

Con respecto a los caminos secundarios, la atención no ha sido puesta en los mismos sino en los sitios localizados a su vera (Beorchia Nigris 1984; Gambier \& Michieli 1986, 1992; Bárcena 2002, 2009, 2010; García 2005, 2007; García et al. 2007; Bárcena et al. 2008; Schobinger 2008; García \& Damiani 2009), salvo el caso de Stehberg (1995), quien consideró algunas prolongaciones orientales (en territorio argentino) de los caminos que registró en el lado chileno.

En síntesis, el conocimiento sobre la vialidad incaica en la provincia de San Juan es escaso. A fin de contribuir a llenar ese vacío de información, se brindan aquí una recopilación y una discusión actualizadas del conocimiento actual sobre la red de caminos utilizados durante el período incaico en ese territorio, y se propone una reconstrucción de la vialidad estatal a partir de los datos actualmente disponibles.

\section{METODOLOGÍA}

El trazado de los tramos del Qhapaq Ñan desde el sur de San Juan hasta el Tambo de Tocota fue identificado directamente en el campo. Su continuación hacia el norte ha sido estimada a partir de las sendas actualmente visibles en las imágenes satelitales del programa Google Earth y de la información de los sitios arqueológicos del área.

Los caminos secundarios del sector occidental han sido estimados a partir del conocimiento directo de la orografía de la zona y de la localización de las vías de menor riesgo y esfuerzo. En todos los casos se ha realizado un análisis crítico de la información a fin de evaluar el grado de probabilidad de filiación incaica de los sitios mencionados. En el caso del sector precordillerano, el trazado responde a la observación directa de un corto tramo aledaño al sitio Matagusanos y a la continuidad de la senda a partir de su identificación en las imágenes satelitales.
Los criterios de identificación del camino incaico considerados son dos: (a) que los tramos propuestos vinculen sitios incaicos o sitios locales con claras señales de dominación incaica; (b) la presencia de cerámica inca o del período incaico directa y recurrentemente asociada a las sendas. Debido a que su interpretación puede resultar equívoca -como ha sucedido a nivel local con algunos sitios de la quebrada de Conconta (Michieli et al. 2005)-, en ausencia de otros elementos la arquitectura no ha sido considerada como criterio de identificación único para adscribir un sitio al período incaico.

\section{LA RECONSTRUCCIÓN DEL SISTEMA VIAL}

El sistema vial incaico se extiende fundamentalmente por el sector occidental de la provincia de San Juan (fig. 1). La información disponible permite identificar el trazado aproximado del Qhapaq Ñan y de algunos de los caminos secundarios asociados.

\section{El Qhapaq Ñan}

Se han expuesto dos posiciones acerca del recorrido del Qapaq Ñan en el norte de San Juan. Una es la de Raffino (1981), para quien desde Guandacol (La Rioja) se dirigía al oeste y pasaba por Pircas Blancas y Pircas Negras para luego tomar el río de los Tambos y cruzar a Chile por el paso de Chollay. Desde Pircas Blancas, a su vez, el camino se habría dirigido hacia el sur, y tras pasar por el tambo de Alcaparrosa habría seguido por la quebrada de río Blanco hasta Angualasto, y de allí hacia el sur (rumbo a Tocota).

Según la segunda posición, el camino principal incaico ingresaba a la provincia de San Juan por el noreste. En algunos mapas (e.g. Levillier 1945, Strube Erdmann 1963), se lo hacía provenir de la localidad de Chilecito (La Rioja), desde donde, con dirección NE-SE, se dirigía hasta el sitio Paso del Lámar tras atravesar la Cuesta de Miranda y pasar cerca de Pagancillo (de la Fuente 1971: 343). En cambio, según Strube Erdmann (1963: 52), pasaba "por Villa Unión (antes Hornillos) a Paso de Lamas, girando luego al o, a Huaco y Jáchal cuyo río sigue hasta caer al valle de Pismanta y por Tocota y Tambillos llegar a Calingasta".

Una alternativa es que el Qhapaq Ñan haya provenido de la Tambería de Guandacol, en el sur de La Rioja ( $22^{\circ} 32^{\prime} 4^{\prime \prime}$ s, $68^{\circ} 33^{\prime} 3^{\prime \prime}$ o), con un rumbo 


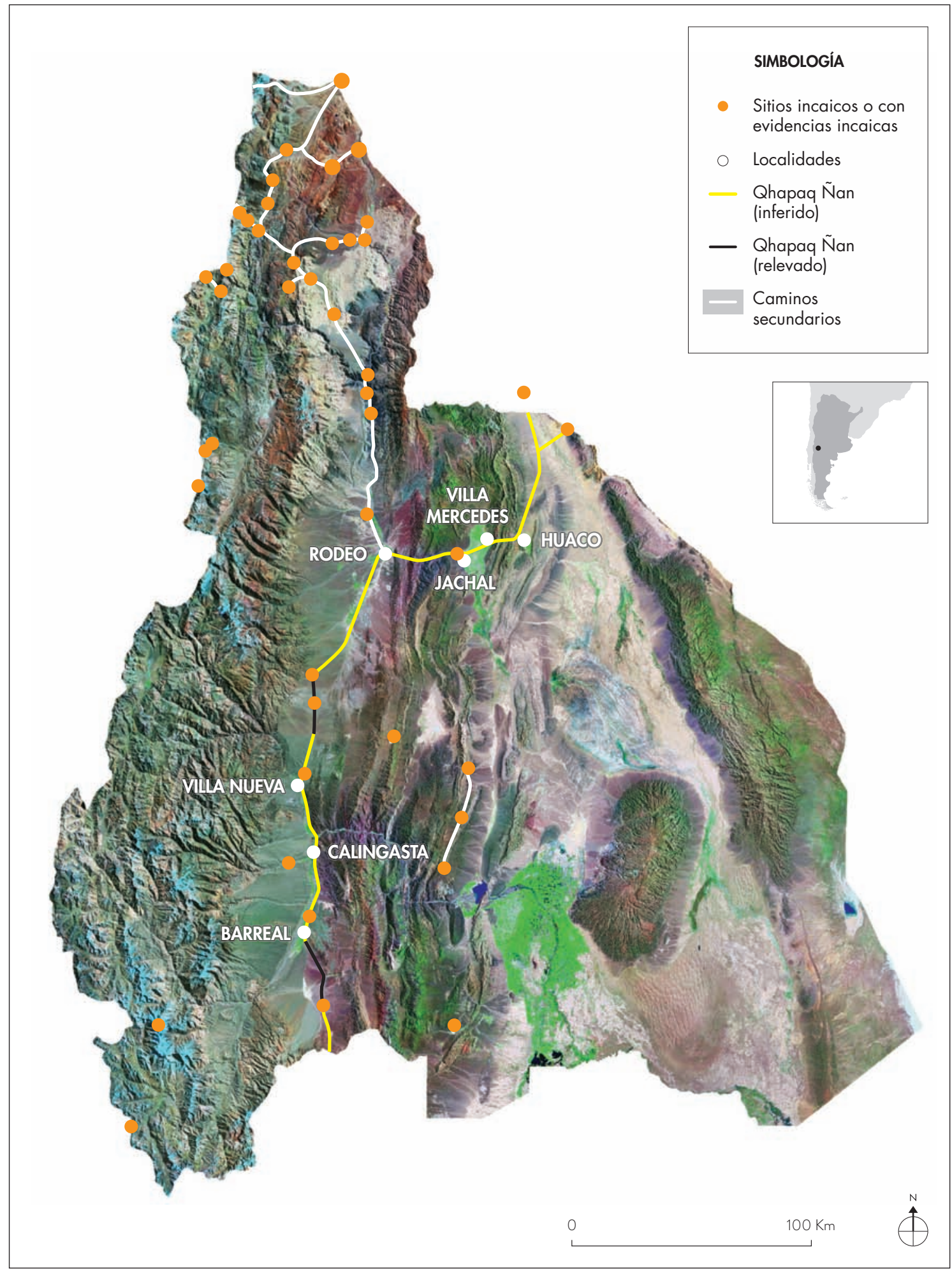

Figura 1. Ubicación de los sitios incaicos o con evidencias incaicas de San Juan y zonas limítrofes, y del trazado de la vialidad estatal. Figure 1. Location of Qhapaq Nan, secondary ways, inca sites, and sites with evidence of Inca presence in San Juan and proximities. 
NNO-SSE hasta aproximadamente $29^{\circ} 52^{\prime} 36^{\prime \prime}$ s, desde donde habría doblado hacia el sso hasta alcanzar el área de la actual localidad de Huaco. Este camino debió coincidir aproximadamente con la Ruta Nacional No 40. Según Aparicio (1940: 252), esta era la opción correcta, ya que este autor señaló que "Debenedetti recorrió, a través de toda la provincia de San Juan, -desde Yalguaraz hasta Guandacol- la huella que allí denominan «camino del Inca»".

Desde Huaco se habría dirigido hacia el sse e internado en la quebrada del río Huaco, donde habría seguido una dirección aproximada E-O. Esta quebrada está muy antropizada, por lo cual las posibilidades de hallar restos de la vialidad incaica son francamente bajas. Lo mismo sucede al salir de la quebrada y entrar en la zona de la actual localidad de Villa Mercedes, uno de cuyos parajes se denomina “Tamberías". Desde allí, el camino habría continuado hacia el ESE, para pasar por la localidad de Pachimoco, uno de los sitios arqueológicos tardíos más grandes de la provincia de San Juan. En este sitio hay un sector en el que aún en la actualidad puede observarse una cantidad relativamente importante de cerámica incaica (García 2010). Luego, el camino habría continuado hacia el E, por la quebrada del Río Jáchal. En este tramo, el río discurre por una estrecha fractura que separa dos bloques montañosos de la precordillera. Aquí, el ensanchamiento de la llanura de inundación del río en los últimos siglos, bien documentado aguas arriba en otros sectores donde se han perdido zonas en las que se habían registrado sistemas de canales de riego, restringe las posibilidades de hallar vestigios de la vialidad incaica en este tramo, si bien es cierto que en el mismo no se han realizado hasta el momento estudios arqueológicos sistemáticos. Luego de pasar el sector precordillerano, el camino pudo dirigirse a la actual localidad de Colola o a la de Rodeo, ubicada unos pocos kilómetros al SE de aquella. La fuerte antropización del sector, que incluye la construcción de un dique y la formación del lago correspondiente, ha borrado cualquier vestigio del Qhapaq Nan que pudiera haber quedado. La situación presenta cierta mejora al sur de Rodeo. Versiones locales hacen pasar el camino por las localidades de Pismanta, Las Flores e Iglesia, pero no se han realizado relevamientos sistemáticos que permitan verificarlas. De todas formas, la multiplicidad de caminos y sendas que surcan este tramo hace extremadamente difícil la identificación, ya que varios de ellos pueden estar superpuestos a la vialidad incaica. De cualquier manera, en este sector el camino incaico debió llevar una dirección general NNE-sso, a juzgar por la ubicación del tambo de Tocota (Rusconi 1962; Berberián et al. 1978). Este se encuentra ubicado aproximadamente a $30^{\circ} 39^{\prime} 27^{\prime \prime}$ s y $69^{\circ} 25^{\prime} 30^{\prime \prime}$ o y 2.550 msnm, sobre la margen derecha del arroyo homónimo. Gambier y Michieli (1992: 15) señalaron la existencia de una tambería al norte de Tocota, en Bauchaceta (ca. $30^{\circ} 30^{\prime}$ s y $69^{\circ} 28^{\prime} \mathrm{o}$ ), pero no brindaron datos sobre su localización, características, registro arqueológico, vinculación con el camino incaico, etc.

Desde Tocota, el camino ha sido registrado por relevamientos recientes (García 2011a, 2012). Luego de subir una barranca, el camino adopta una dirección general $\mathrm{N}$-s. En las inmediaciones de la localidad de Tocota, la senda se interna en un sector con densa vegetación arbustiva, que lo invade a lo largo de 6,9 $\mathrm{km}$ y reduce significativamente su visibilidad y la del material arqueológico asociado. La visibilidad mejora notablemente desde $\mathrm{ca} .30^{\circ} 43^{\prime} 17^{\prime \prime} \mathrm{s}$, mientras que la traza del camino se hace más regular y presenta muy escasa vegetación en su interior.

A ca. $10 \mathrm{~km}$ de Tocota, el camino pasaba por el sitio Caminca 5 (fig. 2a), un conjunto de estructuras que ha sido cortado y parcialmente destruido por la construcción de la Ruta Provincial No 412. En el interior de estas estructuras, al igual que en todo el trazado recorrido, se observaron en 2010 numerosos fragmentos de cerámica incaica y artefactos líticos (fig. 3). En este tramo, el camino presenta cinco segmentos, definidos a partir de leves cambios en su dirección. Se trata de una senda con anchos variables entre 2 y $3 \mathrm{~m}$, que no presenta elementos demarcatorios en sus costados. La extensión total de este tramo es de $25.987,5 \mathrm{~m}$. A lo largo de más de $18 \mathrm{~km}$, hasta su último punto visible, el camino corre en forma más o menos paralela a la Ruta No 412, a una distancia variable entre 6 y 200 m, y en este recorrido se observa una importante afectación por los numerosos cauces esporádicos asociados al río Seco de los Tambillos, que en esta zona corre mayormente al este del camino, El último punto visible de este tramo se ubica aproximadamente a $30^{\circ} 53^{\prime} 29^{\prime \prime}$ s y $69^{\circ} 25^{\prime} 11^{\prime \prime}$ o y $2.200 \mathrm{msnm}$. Algunos kilómetros al sur de este punto, sobre la llanura aluvial del río Seco de los Tambillos, se encuentran los restos bastante destruidos del sitio Tamberías (Debenedetti 1917), cerca de la localidad de Villa Nueva. 
Desde aquí, el camino no es visible en los próximos $67 \mathrm{~km}$ hacia el sur. En este trecho, posiblemente avanzaba a través de las llanuras de inundación de los ríos Castaño y de los Patos, muy alteradas en los últimos 500 años por las esporádicas crecidas que se registran en este tipo de ríos de montaña. Además, la mayor parte de este trayecto está marcada por una gran modificación del fondo del valle de Calingasta por el aprovechamiento de las fértiles tierras para emprendimientos agrícolas y por la instalación de una serie de poblados de diverso tamaño (Calingasta, Tamberías y Barreal). Precisamente desde el sector central de esta última localidad, en la parte distal del piedemonte occidental precordillerano, comienza a observarse el trayecto meridional sanjuanino del camino incaico, desde $31^{\circ} 39^{\prime} 47^{\prime \prime} \mathrm{s}$ (fig. 2b). El mismo ha podido ser reconstruido en una longitud de 30.234 metros a partir del relevamiento directo en el campo. Teniendo en cuenta los principales cambios de rumbo del camino, se han determinado siete tramos. Durante los primeros $17 \mathrm{~km}$, el camino adopta una dirección sse, y luego de cruzar el arroyo El Leoncito sigue un rumbo general aproximado N-s. Hacia 31 54' 55” s, el camino deja de ser reconocible en el paisaje, que en esta zona está totalmente modificado por las crecidas aluviales que bajan ocasionalmente de la precordillera. Sin embargo, en las imágenes satelitales se observan débiles rastros que permiten continuar tentativamente el trayecto hasta el límite interprovincial, en aparente coincidencia con el trazado propuesto por Bárcena (1979: 665).

En este trayecto del valle de Calingasta se observan algunas particularidades interesantes. Por un lado, si bien las características formales del camino son similares a las del trayecto al sur de Tocota (senda limpia sin demarcación ni trabajo adicional), el ancho del camino presenta mayores variaciones: en un primer tramo de $1,5 \mathrm{~km}$ (en el que se destaca un trecho con dos sendas paralelas) es de $c a .1 \mathrm{~m}$, pero luego, en los próximos $12 \mathrm{~km}$ (en los que coincide con la antigua traza del telégrafo), varía entre 4 y $8 \mathrm{~m}$, lo que hace suponer la superposición de un camino más reciente, posiblemente el vinculado con el servicio de mantenimiento de la línea de telégrafo. Luego de cruzar el arroyo El Leoncito, presenta a lo largo de unos 750 metros un ancho de entre 3,5 y $4 \mathrm{~m}$ y una visibilidad regular, pero luego su detección se obstaculiza enormemente debido a las bajadas aluviales que lo cortan transversalmente y en varios sectores es identificable sólo a partir de los fragmentos de cerámica registrados en superficie. En el último tramo, el camino se dirige hacia el SSE y en general guarda un ancho aproximado de $2 \mathrm{~m}$ hasta $c a$. $31^{\circ} 53^{\prime} 48^{\prime \prime}$ s, desde donde comienzan a observarse tres sendas paralelas que corren a corta distancia, sin que sea posible establecer si son coetáneas o tienen distinto origen. Unos $380 \mathrm{~m}$ al sur se agrega una cuarta senda; las cuatro se observan de manera discontinua en los próximos $1.500 \mathrm{~m}$, hasta el final del trayecto recorrido ( $31^{\circ} 55^{\prime} 09^{\prime \prime}$ s). En el sector final, las cuatro sendas tienen un ancho de 0,50 m y están separadas (de o a E) por distancias de $2 \mathrm{~m}, 1,7 \mathrm{~m}$ y $1,7 \mathrm{~m}$.

Otro elemento importante es la ausencia de grandes construcciones a la vera del camino. El primer sitio atravesado por el camino es Piedras Pintadas ( $31^{\circ} 42^{\prime}$ s, $69^{\circ} 46^{\prime}$ o), importante concentración de petroglifos con algunos restos poco visibles de estructuras pequeñas no vinculables a priori con el período incaico. Luego, sobre la superficie de la barranca de la margen izquierda del arroyo El Leoncito se observa una serie de estructuras muy modificadas en la cima de una loma baja. Se trata de dos posibles geoglifos realizados con líneas discontinuas de rocas de mediano tamaño y tres círculos despedrados de entre 1,5 y 1,9 m de diámetro. A $31^{\circ} 53^{\prime} 38^{\prime \prime}$ s y $69^{\circ} 22^{\prime} 55^{\prime \prime}$ o se observa una pequeña estructura formada por una acumulación de clastos y rocas de colores diversos y de pequeño y mediano tamaño. Tiene forma de óvalo, de 0,80 x 0,60 m. En el interior se encontraron varios fragmentos de cerámica incaica. El lugar presenta un marcado desnivel que permite distinguir tres escalones o niveles en el área de la estructura. No se observa en las inmediaciones la existencia de recursos que pudieran brindar una razón práctica para la localización de esta estructura (agua, rocas, sombra, etc.). Finalmente, el camino pasa por el sitio Tambería del Leoncito (Bárcena 1979), que presenta una línea simple e irregular de rocas dispuestas en forma de arco, de $33 \mathrm{~m}$ de largo por $15 \mathrm{~m}$ de ancho, con dos pircados subcirculares y uno oval en su interior (fig. 2c). Al costado oriental del camino se observan algunos alineamientos de rocas que probablemente sean restos de otras estructuras. Evidentemente, a pesar de su nombre, la funcionalidad de este sitio no se vincula con el albergue de gente, depósito de bienes, ni cualquier actividad administrativa asociada con un tambo. Según Bárcena (1979: 688), se trataría de un "sitio ceremonial secundario, de uso más cotidiano que los de altura”. Este es el único sector donde el camino aparece flanqueado por una doble hilera de rocas. 

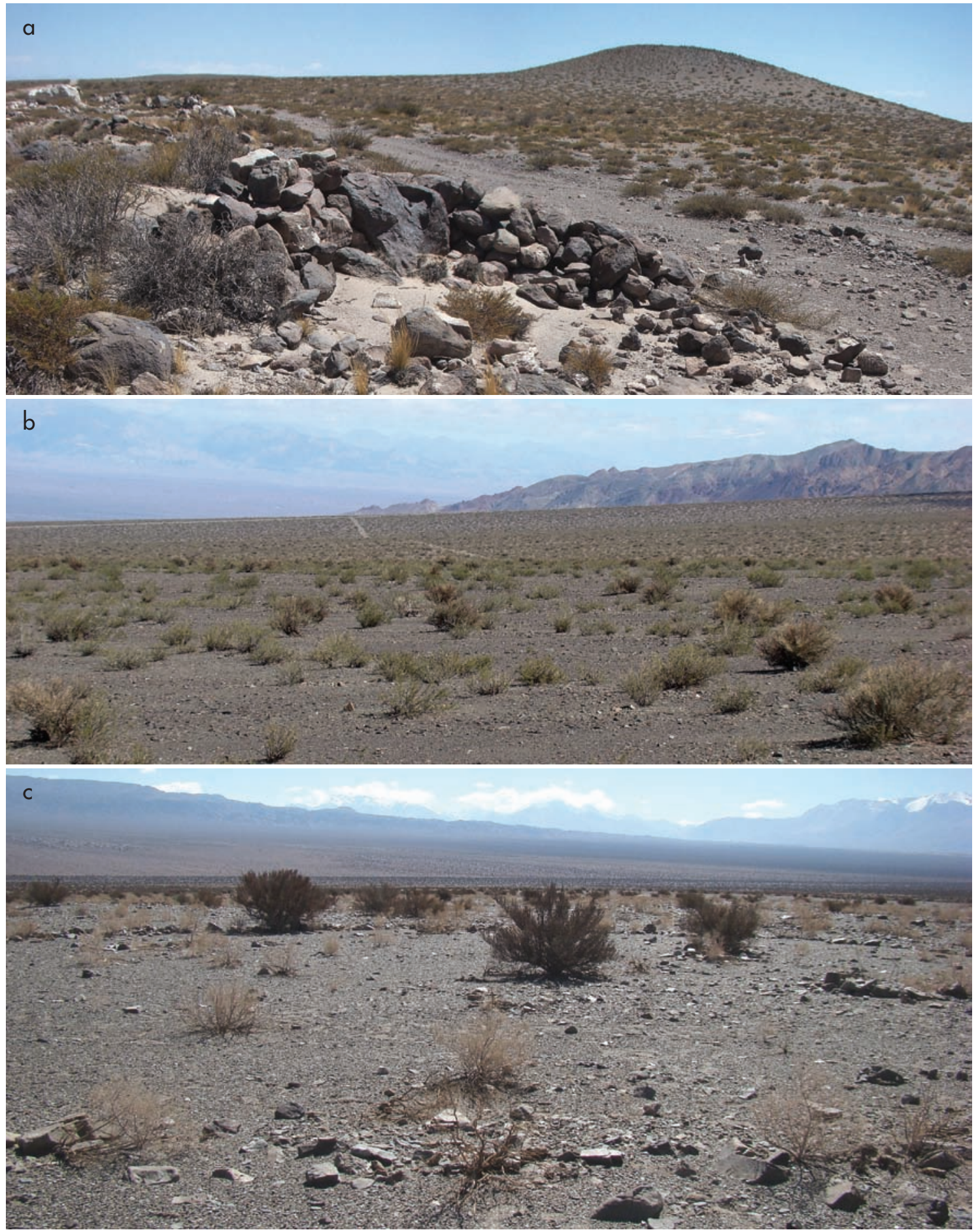

Figura 2. El Qhapaq Ñan al sur de Tocota: a) junto al sitio Caminca 5; b) frente al Barreal del Leoncito; c) Tambería del Leoncito, el sitio más meridional asociado al Qhapaq Nan en San Juan. Figure 2. The Qhapaq Nan south of Tocota: $\boldsymbol{a}$ ) next to the Caminca 5 site; $\boldsymbol{b}$ ) in front of the Barreal del Leoncito; c) Tambería del Leoncito, the southernmost site related to the Qhapaq Nan in San Juan. 

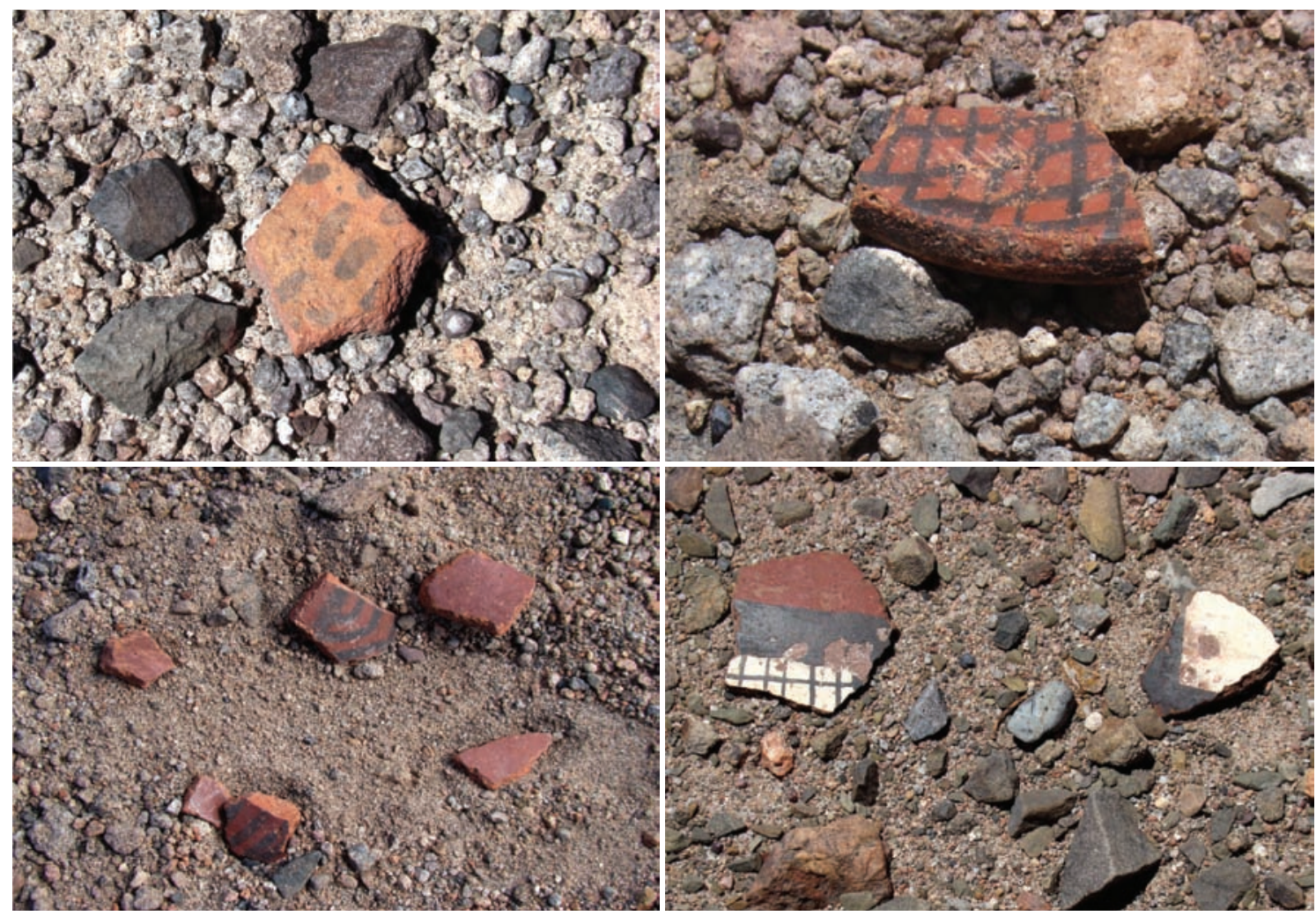

Figura 3. Ejemplos de cerámica asociada al Qhapaq Ñan al sur del sitio Tocota. Figure 3. Examples of ceramics related to the Qhapaq Nan in San Juan, south of the Tocota site.

Estas cuatro estructuras son de baja visibilidad y sus funciones no parecen asociarse con el albergue de quienes transitaban el camino. Desde la Tambería del Leoncito hasta el próximo tambo hay cerca de $53 \mathrm{~km}$ de distancia (el intermedio sitio Ciénaga de Yalguaraz tampoco presenta estructuras incas tradicionales ni puede ser considerado como un tambo típico). Y si se tiene en cuenta que pudo haber un tambo en la localidad de Barreal, entonces el trayecto hasta Tambillos habría sido de más de $80 \mathrm{~km}$ sin tambos intermedios, lo que plantea interesantes interrogantes vinculados con las estrategias de tránsito de este sector.

\section{Los caminos secundarios}

\section{Sector precordillerano}

En la precordillera sanjuanina se han hallado tres tramos de la vialidad incaica. El más largo recorre longitudinalmente la sierra de la Dehesa y habría conectado los tambos de la Dehesa, Matagusanos y el que habría existido en la localidad de Talacasto (Gambier \& Michieli 1992). Localizado por Beorchia Nigris (comunicación personal) en la zona del tambo de Matagusanos, su trazado ha sido identificado a lo largo de $c a .25 \mathrm{~km}$ a través de las imágenes satelitales.

El segundo tramo tiene solo 980 m y está vinculado con el sitio La Invernada, en el sector precordillerano del centro de la provincia. Está constituido por una simple senda de entre 0,8 y $1 \mathrm{~m}$ de ancho que parte desde el sitio hacia el sur a través del valle de la Invernada.

El tercer tramo se encuentra en las cercanías de la localidad de Pedernal (fig. 4) y se trata de una angosta senda de entre 0,6 y $0,8 \mathrm{~m}$ de ancho y de aproximadamente $1 \mathrm{~km}$ de largo que recorre las lomas en las que se encuentran los sitios Pedernal 1 y 2 y baja por la ladera de un cerro hacia el sitio Pedernal 3 (García 2005).

\section{Sector cordillerano norte}

En esta zona se destacan dos ejes longitudinales: el de los ríos Macho Muerto y de la Sal, y el del río Blanco. 


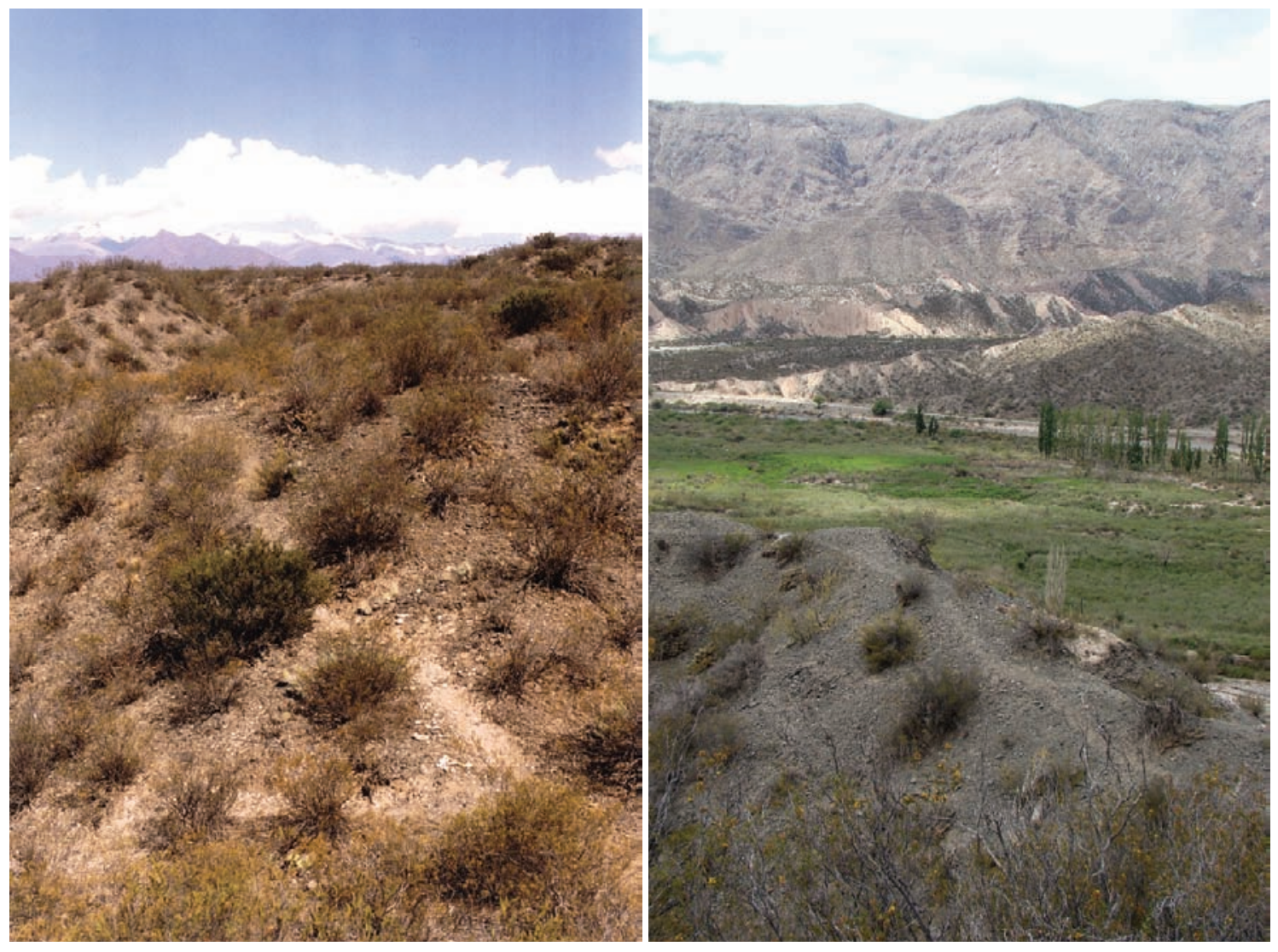

Figura 4. Dos vistas de la senda que une los sitios incaicos precordilleranos de Pedernal. Figure 4. Two views of the path that connects the pre-Andean Inca sites in Pedernal.

Además, deben haber existido numerosos tramos transversales, pero los datos disponibles brindan sustento a solo algunos de ellos.

(1) Eje ríos Macho Muerto y de la Sal. El río del Macho Muerto fluye de sso a NNE en el extremo septentrional de la provincia. Al norte del límite provincial con La Rioja se encuentran sobre este río los sitios incaicos Arroyo Peña Negra y Río Blanco, en la confluencia del río del Macho Muerto con los cauces homónimos. En territorio sanjuanino se ha registrado, aledaño a este río, el sitio Macho Muerto 4, cerca de la confluencia con el río del Inca. Es posible que el camino incaico haya remontado unos $8 \mathrm{~km}$ el río del Inca en dirección NE-So para luego traspasar hacia el sur una divisoria de aguas y dar a uno de los afluentes del río Rincón de la Flecha, que tras recorrer unos $7 \mathrm{~km}$ en dirección NO-SE y N-S vuelca sus aguas en el río de la Sal. Este transita en dirección general $\mathrm{N}$-s ha y a unos $20 \mathrm{~km}$ recibe las aguas del río de los Tambos. En este tramo, se han identificado en las imágenes satelitales dos conjuntos de estructuras distantes entre sí por un poco más de $6 \mathrm{~km}$, ubicado uno a ca. $28^{\circ} 51^{\prime} 36^{\prime \prime}$ s y $69^{\circ} 36^{\prime} 30^{\prime \prime}$ o y otro a $28^{\circ} 48^{\prime}$ $23^{\prime \prime}$ s y $69^{\circ} 35^{\prime} 26^{\prime \prime}$ o.

Desde el arroyo de los Tambillos, el río de la Sal tuerce hacia el SE y vuelve a tomar una dirección N-S hasta desembocar en el río de las Taguas, luego de fluir otros $30 \mathrm{~km}$, pero en este tramo no existen sitios incaicos registrados ni ha sido posible visualizarlos en las imágenes satelitales, a pesar de la presencia de topónimos sugestivos, como el del arroyo Pircas Blancas.

(2) Eje ríos San Guillermo y Blanco. Desde sus nacientes en la cordillera homónima, el río San Guillermo describe un arco y luego toma una dirección general NO-SE. En sus orillas se han registrado los tambos La Gloria (29 $04^{\prime}$ s y $69^{\circ} 30^{\prime}$ o), Pircas Blancas (o San Guillermo, $29^{\circ}$ $08^{\prime}$ s y $69^{\circ} 26^{\prime}$ o) y Huesos Quebrados $\left(29^{\circ} 16^{\prime}\right.$ s, $69^{\circ} 20^{\prime}$ 
o) (Gambier \& Michieli 1986; García et al. 2007; Bárcena 2009). Desde este último sitio, el camino probablemente tomaba una dirección NO-SE, hacia la quebrada de Alcaparrosa, que desemboca en el río Blanco. Allí se encuentra precisamente el Tambo de Alcaparrosa o de la Junta (Gambier \& Michieli 1992; García et al. 2007; Bárcena et al. 2008). Una vez alcanzado el río Blanco, el camino habría seguido su curso hasta el río Jáchal, donde probablemente conectaba con el Qhapaq Nan. En este trecho, se ha reconocido un tambo denominado

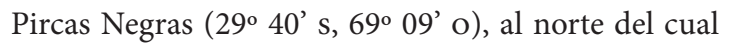
se encuentran otras construcciones que podrían ser incaicas (Schobinger 2008). Además, existe un conjunto de sitios locales tardíos que pudieron haber sido ocupados en época incaica -Lamaral, El Rastrojo, El Jumal, Malimán, etc. (Sacchero 1974)-, pero que aún no han sido estudiados sistemáticamente.

(3) Tramos transversales. Se han identificado cuatro probables tramos transversales principales. Uno habría partido del extremo meridional del valle del Río del Macho Muerto, a la altura del río del Inca, y se habría internado hacia el este remontando el curso de una quebrada de dirección aproximada ONO-ESE, que se origina en la cordillera del Cajón de la Brea. Luego de subir de 4.100 a $5.200 \mathrm{msnm}$, el camino habría bajado hacia el tambo Cajoncito Verde de la Brea y de allí pudo haberse comunicado con el tambo del Arroyo Infiernillo (Gambier \& Michieli 1986), a ca. $3.500 \mathrm{~m}$ de altura.

Un segundo tramo se conecta con las nacientes del río Huasco, en Chile. En territorio argentino, el camino habría discurrido a través de la quebrada de los Tambos, pasando por los sitios Río Tambos Aguas Arriba y Río Tambos Confluencia; luego habría pasado por el tambo Arroyo de los Tambillos y de allí habría continuado en dirección NO-SE, remontando la quebrada de las Pircas para caer en las nacientes del río San Guillermo. Desde allí, pudo tomar hacia el NNE, para alcanzar la quebrada del arroyo Las Olorosas y unir los sitios Alero de los Petroglifos, Tambo Las Olorosas, Tambo del Indio, Santa Rosa y Los Sapitos (Gambier \& Michieli 1986; García et al. 2007; Beorchia Nigris 2014).

Un tramo relativamente corto es el que habría unido los tambos de Pircas Negras y Pircas Blancas, aquel ubicado sobre la quebrada homónima y este sobre el río San Guillermo. Se desconoce si esta senda proseguía hacia el oeste y con qué sitios se habría conectado.
Finalmente, el famoso tambo Valeriano, ubicado sobre el arroyo de los Tambillos, cerca de su confluencia con el río de la Taguas, pudo estar vinculado con el paso Valeriano, con sitios de la vertiente occidental andina y con alguna senda que permitiera el ascenso al cerro El Toro (Schobinger 2008).

\section{Sector cordillerano central}

En esta zona decrece llamativamente la cantidad de sitios incaicos conocidos. Solo se ha registrado un tambo en el río Frío, unos $15 \mathrm{~km}$ al norte del cerro Tórtolas (Stehberg 1995: 195). Además, Schobinger (2008) señala la presencia de un sitio sobre el arroyo La Deidad, si bien no se conocen datos sobre el mismo. Stehberg (1995: 195) ha propuesto dos posibles vías transversales que seguirían los cursos del río Frío y del arroyo de la Deidad, pero no se han registrado trabajos específicos que avalen la existencia de estos caminos. Raffino (1981: 239) pensaba que, desde Angualasto, el Qhapaq Nan "se bifurca seguramente hacia el Paso de las Tórtolas [...] para desembocar en Chile en el Valle del río Elqui”. Según el plano correspondiente, este tramo partiría desde Angualasto hacia el norte y remontaría la quebrada de Colangüil hacia el oeste (o alternativamente la quebrada de Conconta), para cruzar el valle del Cura y llegar al paso de las Tórtolas. Si bien a priori esta ruta parece viable, no se han hallado indicios de su existencia. Más recientemente, se propuso la presencia de varios tambos incaicos y de algunos tramos de vialidad estatal en la quebrada de Conconta (Michieli et al. 2005); sin embargo, posteriormente se constató que estas estructuras correspondían en realidad a habitaciones modernas vinculadas con la construcción en 1955-1956 del camino hacia el valle del Cura (García 2007). Tanto en la quebrada de Conconta como en el sector distal de la quebrada del río Blanco y en la del río del valle del Cura, hacia el norte de su confluencia con aquel, hemos realizado relevamientos que indicaron la ausencia de sitios incaicos. Teniendo en cuenta los antecedentes mencionados, parece probable que los sitios del Río Frío y el Arroyo La Deidad hayan estado vinculados con exploraciones desde el lado occidental andino que no se habrían extendido más hacia el lado oriental.

Más al sur, Raffino (1981: 239) propuso una conexión transversal desde el tambo de Tocota; según Stehberg (1995: 195), este ramal ascendería por el arroyo 


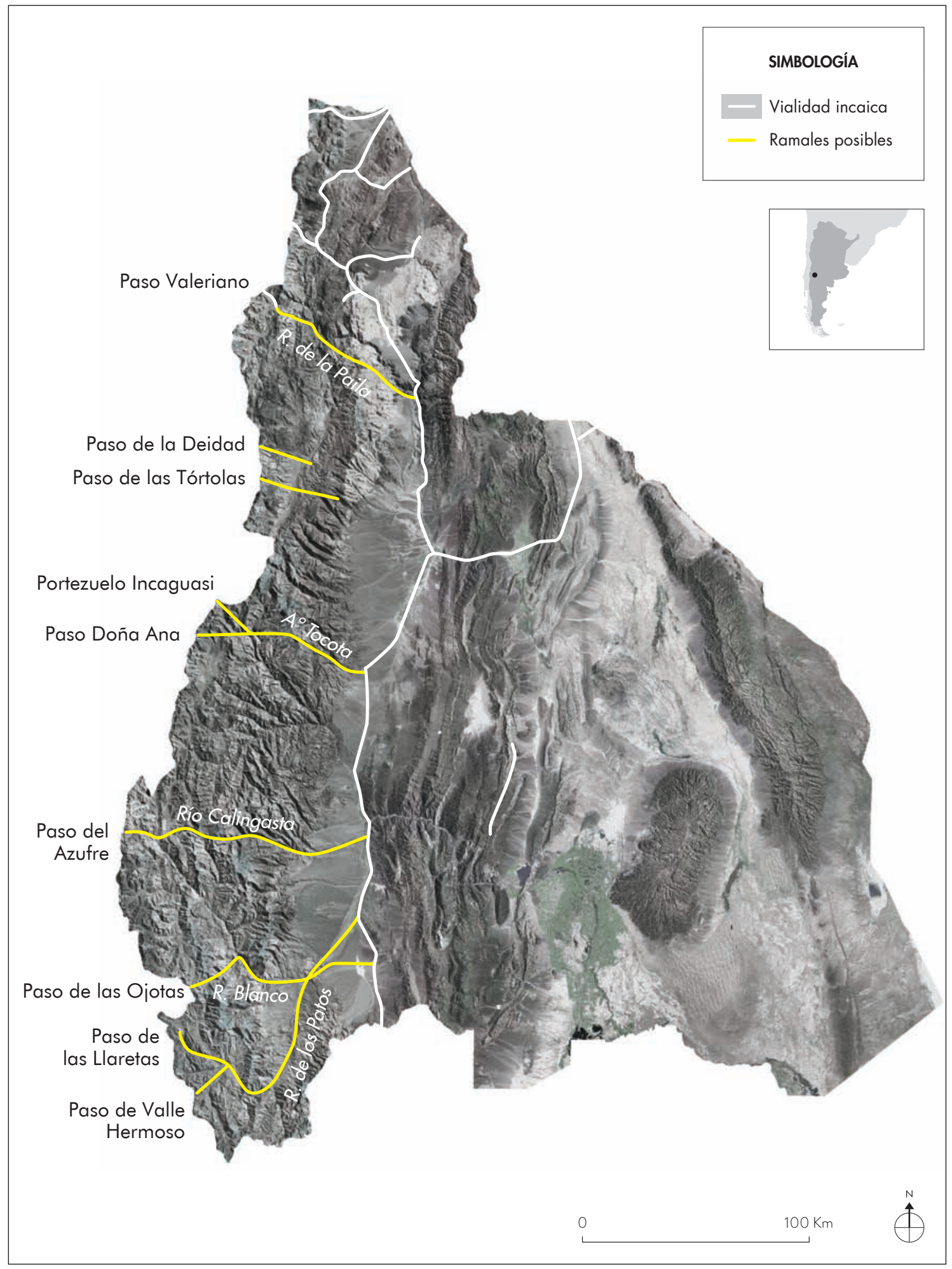

Figura 5. Trazado de la vialidad incaica y ramales posibles propuestos por diversos autores. Figure 5. Inca road layout and possible secondary roads as proposed by several authors. 
Tocota, cruzaría por el paso Doña Ana y continuaría en Chile por el río Hurtado (fig. 5). Sin embargo, en territorio argentino no se han realizado estudios que hayan constatado la presencia del camino o de sitios incaicos al oeste del tambo de Tocota.

\section{Sector cordillerano sur}

En el suroeste cordillerano sanjuanino se han registrado escasos sitios incaicos y, al igual que en el sector central, no se observa una toponimia específica, en franco contraste con la zona septentrional. En esta zona se han propuesto varios ramales trasandinos. Raffino (1981: 239) señaló la posible existencia de una vía de comunicación que habría unido Calingasta con la región del río Hurtado, a través de la quebrada del río Castaño Viejo y el paso de Portillo. Para Stehberg (1995: 84-88), habría otros cuatro: (1) uno seguiría el curso del río Calingasta, y luego posiblemente bordearía los arroyos de la Totora y de Araya y los ríos de las Salinas y del Calderón, atravesaría el paso del Azufre ( $31^{\circ} 18^{\prime} \mathrm{s}, 70^{\circ} 32^{\prime}$ o) y se comunicaría con la cuenca alta del río Illapel, en Chile. En el lado argentino, el único sitio incaico conocido sobre el río Calingasta es Barrealito (Debenedetti 1917), localizado cerca de la confluencia con el río de los Patos y a $100 \mathrm{~km}$ en línea recta del paso del Azufre. Entre Barrealito y la frontera con Chile no se han registrado aún sitios o tramos viales que permitan comprobar la existencia de aquel ramal. (2) El segundo tramo pasaría por el paso de las Ojotas ( $31^{\circ} 54^{\prime} 30^{\prime \prime} \mathrm{s}, 70^{\circ} 15^{\prime} 50^{\prime \prime} \mathrm{O}$ ) y seguiría el curso del río Blanco rumbo a El Leoncito. (3) Un tercer camino remontaría los ríos de los Patos y Teatinos, para cruzar a Chile por el paso de las Llaretas $\left(32^{\circ}\right.$ $09^{\prime}$ s, $70^{\circ} 19^{\prime} \mathrm{o}$ ). Desde el paso de las Llaretas hasta la localidad de Barreal, este ramal tendría unos $150 \mathrm{~km}$ de extensión, en los cuales no se han encontrado aún evidencias incaicas. (4) Un cuarto ramal provendría del río de los Patos y cruzaría a Chile por el paso de Valle Hermoso ( $30^{\circ} 47^{\prime}$ s, $70^{\circ} 16^{\prime}$ o). En este lugar hay un sitio incaico denominado Tambillo del Paso de Valle Hermoso (Bárcena 1999: 168), del cual solo se ha brindado un plano de estructuras, pero se carece de información sobre el registro arqueológico asociado. Según este autor, "con nuestro reconocimiento y hallazgo comprobamos la senda e instalación inca en el sector alto de Valle Hermoso" (Bárcena 2001: 290), por lo que la existencia del supuesto ramal transversal queda restringida a la zona del paso. Hacia el oriente, no se han registrado hallazgos que permitan corroborar su continuidad por el territorio sanjuanino.

En resumen, como ocurre con el posible camino transversal del arroyo Tocota, no se han realizado hallazgos que permitan verificar estas propuestas; en el primer caso, por falta de investigaciones y en los restantes por falta de hallazgos, a pesar de haberse realizado relevamientos sistemáticos.

\section{DISCUSIÓN}

Desde hace casi cien años se han realizado diversas observaciones sobre el registro incaico y el Qhapaq $\tilde{N} a n$ en San Juan. La cantidad de sitios del período incaico identificados en esta provincia es importante, sobre todo en la región de San Guillermo, en el extremo noroeste, situación que sugeriría que el conocimiento sobre la vialidad estatal podría también ser avanzado. Sin embargo, en general el estudio de los sitios incaicos no ha sido acompañado por un rastreo de las sendas que los comunicaban con otros componentes del sistema de asentamiento/comunicación y por un registro y análisis del material arqueológico asociado. Como reflejo de esta situación, solo se ha elaborado un artículo específico sobre relevamientos de la vialidad incaica provincial (García 2011a), si bien en otros se hecho realizado alusiones al tema.

Salvo el caso del Qhapaq Ñan en el sur de Iglesia y en Calingasta, en gran medida la vialidad incaica ha sido inferida a partir de la ubicación de los sitios incaicos, por lo que su correcta localización resulta muy importante. Como ya advirtiera Bárcena $(2009,2010)$ para los casos de La Dehesa, Infiernillo y Tambo del Indio, y como pudieron observar García et al. (2007) en la región de San Guillermo, varios de los sitios incaicos mencionados en los trabajos locales no han sido aún ubicados con precisión, lo que puede llevar a errores al momento de trazar posibles tramos de la vialidad estatal. En relación con este riesgo, otro foco de atención es el de la identificación efectiva de los sitios como componentes del sistema incaico de asentamiento. Por ejemplo, la adscripción de sitios al período incaico basada exclusivamente en sus características arquitectónicas ha mostrado recientemente constituir una vía de acción muy problemática (Michieli et al. 2005; García 2007), por lo que es conveniente recurrir a diversos elementos para 
realizar una identificación correcta. Con respecto a este punto, muchos de los sitios incaicos de la provincia de San Juan han sido simplemente mencionados, sin que se hayan publicado fotografías, dibujos o descripciones de materiales que permitan evaluar y comprobar la adscripción étnica propuesta. Entre estos sitios se encuentran los del Arroyo La Deidad, Río Frío, Valle Hermoso, Los Ocúcaros, Mina El Fierro, Gualilán, Bauchaceta, Tambo del Indio, Las Olorosas y Tambillos (San Guillermo). En rigor, se han publicado estudios con cierto grado de detalle de solo dos sitios: Tocota (Berberián et al. 1978) y Alcaparrosa (Bárcena et al. 2008); mientras que otros tres se encuentran recién en estudio (Paso del Lámar, La Invernada y Pedernal). Indudablemente, la futura realización de trabajos sistemáticos en una mayor cantidad de sitios y la publicación de ubicaciones más precisas y de mayor información contextual contribuirán a mejorar las posibilidades de éxito en la localización de las sendas que los unían y en su contrastación con relevamientos de campo. De la misma forma, un estudio detallado de los sitios incaicos puede brindar información sobre su funcionalidad y contribuir así a comprender mejor los intereses que movían la utilización de la vialidad estatal en los distintos sectores.

En relación con el trazado general presentado en este trabajo, cabe realizar algunas observaciones. En primer lugar, llama la atención la importante cantidad de sitios registrados en el noroeste sanjuanino, en la zona conocida como San Guillermo. Dilucidar la razón de esta ocupación intensiva puede contribuir a entender otros aspectos de la dominación incaica, por ejemplo, la dinámica de la anexión de los sectores andinos orientales. Si bien se ha propuesto una actividad específica como motor de esa ocupación -la explotación de la lana de vicuñas (Gambier \& Michieli 1986)-, no se han realizado estudios sistemáticos que permitan verificar esta hipótesis o explorar otras alternativas.

La elevada cantidad de sitios del sector cordillerano norte contrasta con la escasez de los sectores central y meridional. En estos, los hallazgos se encuentran muy cerca de la zona limítrofe entre Chile y Argentina (Río Frío, Arroyo La Deidad, Cerro Mercedario, Valle Hermoso), y llamativamente, si bien se vinculan con probables rutas transversales naturales, no se han encontrado sitios en el sector oriental con los que puedan estar conectados. De ahí que, al igual que sucede con el Cerro El Toro y quizás con Paso Valeriano, es probable que estos sitios estén en realidad vinculados fundamentalmente con la ocupación incaica del lado chileno y, a lo sumo, con la exploración de algunos sectores aledaños por el lado oriental (sin que dicha exploración se haya concretado en vías de comunicación con las zonas extrandinas recurrentemente utilizadas).

Por otra parte, el hecho de que hasta el momento no se haya comprobado la existencia de los ramales transversales sugeridos por algunos autores no significa que algunos de ellos (sobre todo los aún no relevados, como el del arroyo Tocota) no hayan sido efectivamente utilizados.

Con respecto a los tramos de caminos precordilleranos conocidos, si bien son escasos, sugieren que la red vial en esta región era compleja y probablemente discurría por sectores muy afectados en los últimos quinientos años por agentes naturales y culturales ( $\mathrm{y}$ por ende de muy baja visibilidad actual), como la llanura de inundación del río San Juan o el valle interprecordillerano de Gualilán. De hecho, si bien la documentación temprana exhibe pruebas de la dominación incaica del sector donde actualmente se ubica la ciudad de San Juan, la alteración antrópica de la misma ha impedido el hallazgo de evidencias, incluidos los caminos incaicos.

Finalmente, parecería claro que el sector oriental de la actual provincia de San Juan (al este del valle de Tulum) no estaba controlado por el Estado inca-aunque probablemente se encontrara en exploración (García 2011b)-, por lo que la ausencia actual de vialidad imperial vinculada con este sector podría responder a su efectiva ausencia más que a una falta de investigaciones en el área.

\section{PERSPECTIVAS Y AGENDA FUTURA}

Teniendo en cuenta el conocimiento actual sobre el tema, los futuros trabajos vinculados con la vialidad incaica en San Juan deberían abordar cuatro aspectos principales:

(1) El rastreo a pie de las evidencias del Qhapaq Nan que pudieran haber sobrevivido desde Tocota hacia el norte. Si bien se tiene una idea aproximada de su localización, es importante precisar su vinculación con algunas localidades tradicionalmente asociadas al mismo, como Pismanta y Angualasto. Por otra parte, es imperioso hallar elementos que permitan verificar su paso a lo largo del curso del río Jáchal y constatar su recorrido al norte de Huaco, ya que la gran alteración 
sufrida por estos sectores pone en riesgo la posibilidad de constatar la información oral (no arqueológica) relacionada con los mismos.

(2) El relevamiento detallado de los múltiples tramos transversales recurrentemente propuestos como vías de unión de las dos vertientes cordilleranas. Esta inspección debe realizarse fundamentalmente en los sectores cordilleranos de los ríos de los Patos y Calingasta, y del arroyo Tocota. Además, se requiere la prospección de los tramos medio y distal del río Frío y del arroyo de la Deidad, para constatar si la presencia de evidencias incaicas alcanza sectores más cercanos al valle del Cura o se mantiene restringida a los espacios cordilleranos más altos. Todo este conjunto de relevamientos es sumamente necesario a fin de clarificar la situación observable en la mayoría de los mapas sobre el sistema vial incaico, en los que la señalización de trayectos "posibles" termina brindando una imagen gráfica sobredimensionada, que en algunas zonas podría distar mucho de la realidad. En el caso de la zona noroeste de la provincia (San Guillermo), si bien la situación parecería estar más clara, también es necesaria la determinación de los recorridos reales de los tramos que unirían los sitios allí registrados.

(3) La ampliación del registro vial precordillerano. Los tramos conocidos en esta región geomorfológica son escasos, y conocer las rutas precordilleranas que vinculaban el Qhapaq Nan con los sitios de los valles de la franja longitudinal central de la provincia puede contribuir a conocer la importancia asignada por el Estado a cada zona y su integración diferencial al aparato administrativo y económico.

(4) El análisis del registro arqueológico asociado a la vialidad incaica. Ya se trate de la abundante cerámica que generalmente se encuentra esparcida a lo largo de estos caminos (fig. 5) o del registro de los sitios directamente vinculados con ellos, la información que albergan es fundamental para analizar las características y escala espacial de la movilización de gente y productos (Uribe \& Cabello 2005), en vistas a la reconstrucción del uso de los distintos tramos.

En definitiva, resulta claro que los esfuerzos vinculados con el estudio de la dominación incaica regional se han centrado en la búsqueda de sitios y han prestado escasa atención a la vialidad estatal, cuya reciente revalorización requiere un cambio de orientación dirigido a su fehaciente detección y análisis. Una más completa reconstrucción del Qhapaq Nan y del sistema vial secundario sanjuanino no solo brindará importante información sobre la movilidad de bienes y personas durante el período incaico, sino que además contribuirá a mejorar nuestra comprensión de los mecanismos de anexión y control de las poblaciones locales y a enriquecer de esta forma el conocimiento sobre la frontera sudoriental del Collasuyo.

RECONOCIMIENTOS Este trabajo se realizó en el marco de proyectos financiados por el CONICET, la Universidad Nacional de Cuyo y la Universidad Nacional de San Juan. Agradezco a Christian Vitry y Carlos González su gentil invitación para participar del Qhapaq Nan I. Taller Internacional en torno al Sistema Vial Inkaico, y a Sergio Martín y a un evaluador anónimo por sus valiosas sugerencias.

\section{REFERENCIAS}

Aparicio, F. DE., 1940. Ranchillos, tambo del Inca en el camino a Chile. Anales del Instituto de Etnografía Americana I: 245253, Mendoza.

BÁRCENA, J., 1979. Informe sobre recientes investigaciones arqueológicas en el N.O. de la Provincia de Mendoza (valle de Uspallata y zonas vecinas) (con especial referencia al Período Incaico). En Actas VII Congreso de Arqueología de Chile, vol. II, pp. 661-692. Santiago: Kultrún.

BÁRCENA, J., 1999. Contribución a los estudios interdisciplinarios, arqueológicos y etnohistóricos, sobre la dominación inka en el centro oeste argentino. En Actas XII Congreso Nacional de Arqueología Argentina, vol. 1, pp. 163-178. La Plata: Universidad Nacional de La Plata.

BÁRCENA, J., 2001. Consideraciones generales y avances particulares sobre la dominación incaica en el centro oeste argentino. En Actas XIII Congreso Nacional de Arqueología Argentina, vol. 1, pp. 277-296. Córdoba.

BÁrCenA, J., 2002. Perspectivas de los estudios sobre la dominación inka en el extremo austral-oriental del Kollasuyu. Boletín de Arqueología PUCP 6: 277-300.

BÁrCENA, J., 2009. Avances 2003-2004 sobre arqueología y etnohistoria de la dominación inca del centro oeste argentino. En Problemáticas de la arqueología Contemporánea (III), A. Austral \& M. Tamagnini, Comps., pp. 31-47. Río Cuarto: Universidad Nacional de Río Cuarto.

BÁrcena, J., 2010. Aportes 2000-2001 al conocimiento de la dominación incaica del centro oeste argentino. En Arqueología argentina en los inicios de un nuevo siglo (III), F. Oliva, N. de Grandis \& J. Rodriguez, Comps., pp. 131-142. Rosario: Laborde.

Bárcena, J.; P. Cahiza, J. García \& S. Martín, 2008. Arqueología del sitio inka de La Alcaparrosa: Parque Nacional San Guillermo Provincia de San Juan, Argentina. Mendoza: INCIHUSA-CONICET. 
Beorchia, A., 1984. El enigma de los santuarios indígenas de alta montaña. San Juan: CIADAM.

Beorchia, A., 2014. Qhapaq Ñan. San Juan: Barrick.

Berberián, E.; J. Martín de Zurita \& J. Gambetta, 1978. Investigaciones arqueológicas en el yacimiento incaico de Tocota (Prov. de San Juan, Rep. Argentina). Anales de Arqueología y Etnología XxxiI-XxxiII: 173-210, Mendoza.

Debenedetti, S., 1917. Investigaciones arqueológicas en los valles preandinos de la provincia de San Juan. Publicaciones de la Sección Antropología 15. Buenos Aires: Universidad de Buenos Aires.

De LA Fuente, N., 1971. Las culturas prehispánicas de la provincia de La Rioja: panorama general. Córdoba: Museo Arqueológico Regional Aníbal Montes.

Gambier, M. \& C. Michieli, 1986. Construcciones incaicas y vicuñas en San Guillermo. Un modelo de explotación económica de una región inhóspita. Publicaciones 15: 3-78, San Juan.

GAmbier, M. \& C. Michieli, 1992. Formas de dominación incaica en la provincia de San Juan. Publicaciones 19: 11-19, San Juan.

García, A., 2005. Hallazgo del "Fuerte del Inga" del Acequión. En Actas del VII Encuentro de historia argentina y regional, pp. 150-159. Mendoza.

GARCíA, A., 2007. El control incaico del área del Acequión (sur de San Juan). En Actas del XvI Congreso Nacional de Arqueología Argentina II, pp. 487-491. Jujuy.

García, A., 2010. Arqueología prehistórica de San Juan. La conquista indígena de los dominios del cóndor y el guanaco. San Juan: EFU.

GArCía, A., 2011a. El Camino del Inca entre Tocota y Villa Nueva (valle de Iglesia, San Juan). Revista del Museo de Antropología 4: 89-98, Córdoba.

GARcíA, A., 2011b. La frontera sudoriental del Tawantinsuyu. Sociedades de paisajes áridos y semi-áridos 5: 163-175, Río Cuarto.

GARCíA, A., 2012. Breve revisión de un proceso multifacético: la integración del centro oeste argentino al Estado Inca. En Arqueología y antropología en la encrucijada: desafíos actuales en la investigación social, M. de Haro; A. Rocchietti, M. Runcio, O. Hernández de Lara \& M. Fernández, Eds., pp. 57-66. Buenos Aires: Centro Investigaciones Precolombinas.

García, A.; N. Fernández, O. Damiani, C. Jofré, A. Carrizo, A. Eguaburo \& C. Cabello, 2007. Relevamiento arqueológico del área del Parque Nacional San Guillermo y zonas adyacentes. En Diversidad biológica y cultural en los altos Andes centrales de Argentina. Línea de base de la reserva de biósfera San Guillermo-San Juan, E. Martínez, Ed., pp. 225250. Mendoza: Inca.

García, A. \& O. DAmiani, 2009. Nuevas evidencias de la dominación incaica y la ocupación indígena tardía en el centro-sur de San Juan. En Problemáticas de la arqueología contemporánea (III), A. Austral \& M. Tamagnini, Comps., pp. 933-937. Río Cuarto: Universidad Nacional Río Cuarto.

HysLoP, J. 1984. The Inka Road system. Nueva York: Academic Press.

Levillier, R. 1945. Don Francisco de Toledo, supremo organizador del Perú, tomo iII. Buenos Aires: Espasa-Calpe.

Michieli, C., 2001. Tambos incaicos del centro de San Juan: su articulación regional. Scripta Nova. Revista electrónica de geografía y ciencias sociales 70: 1-22. http://www.ub.edu/ geocrit/sn-70.htm [Citado 17-01-16].

Michieli, C.; A. VArela \& M. Riveros, 2005. Investigaciones arqueológicas y protección de las instalaciones incaicas de la quebrada de Conconta (San Juan, Argentina). San Juan: Universidad Nacional de San Juan.

Raffino, R., 1981. Los incas del Collasuyu. La Plata: Ramos Americana.

Rusconi, C., 1962. La tambería prehispánica de Tocota (San Juan). Revista del Museo de Historia Natural de Mendoza XIV (1-4): 25-30.

Sacchero, P., 1974. Prospección arqueológica en el valle del río Blanco, Jáchal, San Juan. Anales de Arqueología y Etnología xxix-Xxxi: 37-65, Mendoza.

Schobinger, J., (Ed.). 2008. La momia del cerro El Toro. Mendoza: Facultad de Filosofía y Letras, Universidad Nacional de Cuyo.

Stehberg, R., 1995. Instalaciones incaicas en el norte semiárido de Chile. Santiago: Diвam.

Strube, L., 1963. Vialidad imperial de los Incas. Desde Colombia hacia Chile central y sur de Mendoza (Argentina) con inclusión de sus proyecciones orientales. Instituto de Estudios Americanistas, serie histórica xxxıII. Córdoba: Universidad Nacional de Córdoba.

Uribe, M. \& G. Cabello, 2005. Cerámica en el camino: los materiales del río Loa (norte grande de Chile) y sus implicaciones tipológicas y conductuales para la comprensión de la vialidad y la expansión del Tawantinsuyo. Revista Española de Antropología Americana 35: 75-98. 